\title{
A ADMISSIBILIDADE DA RECONVENÇÃO NAS AÇÕES CIVIS PÚBLICAS
}

\author{
José Antonio Remedio ${ }^{1}$ \\ Roberto Yuzo Hayacida ${ }^{2}$
}

\section{RESUMO:}

A pesquisa objetiva analisar a admissibilidade da reconvenção nas ações civis públicas. $\mathrm{O}$ objeto da ação civil pública é a proteção dos direitos difusos, coletivos e individuais homogêneos. Em face das peculiaridades quanto ao objeto e aos legitimados ativos da ação civil pública, doutrina e jurisprudência controvertem-se sobre o cabimento da reconvenção na ação. O método adotado é o dedutivo, com base em pesquisa legal, doutrinária e jurisprudencial. Em conclusão, tem-se que não é admissível a reconvenção na ação civil pública para a proteção dos direitos difusos e coletivos, sendo cabível o instituto, porém, quanto aos direitos individuais homogêneos.

Palavras-chave: Ação Civil Pública; Direitos Difusos e Coletivos; Direitos Individuais Homogêneos; Reconvenção; Reconvenção em Ação Civil Pública.

\section{THE ADMISSIBILITY OF COUNTERCLAIM ON PUBLIC CIVIL ACTIONS}

\begin{abstract}
:
The research aims to analyze the admissibility of counterclaim in public civil actions. The object of the public civil action is the protection of diffuse, collective and individual homogeneous rights. Due to its peculiarities and the legitimized part of the public civil action, doctrine and jurisprudence are controversial on the suitability of the counterclaim in the action. The method adopted is the deductive, based on legal, doctrinal and jurisprudential research. In conclusion, a counterclaim in a public civil action for the protection of diffuse and collective rights is not admissible; however, regarding the homogenous individual rights, the counterclaim is applicable.
\end{abstract}

Keywords: Public Civil Action; Diffuse and Collective Rights; Homogeneous Individual Rights; Counterclaim; Counterclaim in a Public Civil Action.

\section{INTRODUÇÃO}

O Código de Processo Civil de 2015 (CPC/2015) trouxe diversas alterações e inovações em relação às disposições constantes do Código de Processo Civil de 1973 (CPC/1973), como se verifica, por exemplo, no tocante ao instituto da reconvenção.

\footnotetext{
${ }^{1}$ Doutor em Direito do Estado pela Pontifícia Universidade Católica de São Paulo (PUCSP). Professor de Graduação e Pós-graduação (Mestrado) em Direito da Universidade Metodista de Piracicaba (UNIMEP). Professor de Graduação em Direito do Centro Universitário Adventista de São Paulo (UNASP). Promotor de Justiça do Ministério Público do Estado de São Paulo Aposentado. Advogado. jaremedio@yahoo.com.br

${ }^{2}$ Mestrando em Direito pela Universidade Metodista de Piracicaba (UNIMEP). Procurador do Estado de São Paulo.yuzoha@ig.com.br
} 
A Lei 5.869/1973 - CPC/1973, tratava da reconvenção nos arts. 315 a 318 (BRASIL, 1973), dispondo a respeito que: "o réu pode reconvir ao autor no mesmo processo, toda vez que a reconvenção seja conexa com a ação principal ou com o fundamento da defesa" (art. 315, caput); e, "não pode o réu, em seu próprio nome, reconvir ao autor, quando este demandar em nome de outrem" (art. 315, parágrafo único).

A Lei 13.105/2015 - CPC/2015, por sua vez, trata da reconvenção em seu art. 343, nos seguintes termos (BRASIL, 2015): "na contestação, é lícito ao réu propor reconvenção para manifestar pretensão própria, conexa com a ação principal ou com o fundamento da defesa" (art. 343, caput); e, "se o autor for substituto processual, o reconvinte deverá afirmar ser titular de direito em face do substituído, e a reconvenção deverá ser proposta em face do autor, também na qualidade de substituto processual” (art. 343, § 5).

A substancial alteração dada ao instituto da reconvenção no CPC/2015 em comparação com o CPC/1973, relativamente à sua aplicação nos casos de substituição processual, torna o debate sobre o tema bastante convidativo, principalmente em face da possibilidade de aplicação da reconvenção nas ações coletivas, entre as quais a ação civil pública, objeto específico da presente pesquisa, uma vez que predomina na doutrina e na jurisprudência o entendimento no sentido de que se trata de substituição processual a natureza jurídica da legitimidade ativa para o ajuizamento da ação civil pública.

Os direitos transindividuais, entre os quais os direitos difusos e coletivos, assim como os direitos individuais homogêneos, são protegidos por meio vários instrumentos processuais de tutela coletiva, com destaque à ação civil pública.

De um lado, a natureza dos direitos protegidos pela ação civil pública, em geral de caráter difuso, coletivo ou individual homogêneo, e a característica peculiar da legitimidade ativa para ajuizamento da ação, tradicionalmente tida como substituição processual, induzem a sustentar a inadmissibilidade do instituto da reconvenção em relação a referida espécie de ação.

De outro lado, o CPC/2015 (BRASIL, 2015), ao tratar da reconvenção e estatuir no $\S$ $5^{\circ}$ do art. 343 que, "se o autor for substituto processual, o reconvinte deverá afirmar ser titular de direito em face do substituído, e a reconvenção deverá ser proposta em face do autor, também na qualidade de substituto processual”, possibilita pensar na admissibilidade do instituto processual em relação à ação civil pública. 
O objeto da pesquisa é analisar se o instituto da reconvenção previsto no art. 343 do CPC/2015 é aplicável à ação civil pública, espécie de instrumento jurisdicional de tutela coletiva.

Quanto à estrutura, a pesquisa trata inicialmente dos direitos difusos, coletivos e individuais homogêneos, em seguida da ação civil pública no tocante a seu objeto e legitimidade ativa, na sequência dos caracteres gerais da reconvenção, e por fim da reconvenção em relação à ação civil pública.

A hipótese apresentada é no sentido de que não é admissível a reconvenção na ação civil pública quando o objeto protegido for direito transindividual, seja ele difuso ou coletivo, cabendo o instituto da reconvenção, porém, quando o objeto protegido forem direitos individuais homogêneos.

O método adotado é o dedutivo, por meio de pesquisa legal, doutrinária e jurisprudencial.

\section{DIREITOS DIFUSOS, COLETIVOS E INDIVIDUAIS HOMOGÊNEOS}

A Constituição Federal brasileira instituiu um Estado Democrático de Direito que assegura a proteção e a efetivação dos direitos individuais, dos direitos transindividuais, sejam eles difusos ou coletivos stricto sensu, e dos direitos individuais homogêneos. A Lei Maior de 1988, no Título II, Capítulo I, art. 5ª a dispor sobre os direitos e garantias fundamentais, refere-se expressamente aos direitos individuais e coletivos.

$\mathrm{O}$ ordenamento jurídico brasileiro, relativamente à tutela coletiva, contém dispositivos normativos que contemplam tanto a proteção dos direitos como dos interesses coletivos lato sensu.

Os termos "interesses" e "direitos", embora possuam significados diferentes em sua origem, no Brasil, com o advento do Código de Defesa do Consumidor, são tratados como sinônimos, conforme se constata do estatuído no art. 81, parágrafo único, incisos I a III, da Lei 8.078/90 (REMEDIO, 2015, p. 883).

Os interesses individuais são aqueles que "se restringem à esfera de atuação de cada pessoa e cujo exercício depende de uma ação voluntária do indivíduo” (MANCUSO, 2011, p. 53).

Revista de Processo, Jurisdição e Efetividade da Justiça | e-ISSN: 2525-9814 | Brasília | v. 3 | n. 1 | p. 97 - 115 | Jan/Jun. 2017. 
A Lei n. 8.078/1990, conhecida como Código de Defesa do Consumidor, ao dispor sobre a defesa do consumidor em juízo, apresenta no parágrafo único do art. 81 a definição dos interesses ou direitos difusos, coletivos e individuais homogêneos, nos seguintes termos (BRASIL, 1990):

a) interesses ou direitos difusos, assim entendidos "os transindividuais, de natureza indivisível, de que sejam titulares pessoas indeterminadas e ligadas por circunstâncias de fato" (inciso I);

b) interesses ou direitos coletivos, assim tidos "os transindividuais, de natureza indivisível de que seja titular grupo, categoria ou classe de pessoas ligadas entre si ou com a parte contrária por uma relação jurídica base" (inciso II);

c) interesses ou direitos individuais homogêneos, assim entendidos "os decorrentes de origem comum" (inciso III).

O Supremo Tribunal Federal, ao julgar o Recurso Extraordinário n. 163.231-SP, firmou o entendimento no sentido de que (BRASIL, 2001): os "interesses difusos são aqueles que abrangem número indeterminado de pessoas unidas pelas mesmas circunstâncias de fato"; os interesses coletivos são "aqueles que pertencem a grupos, categorias, ou classes de pessoas determináveis, ligadas entre si ou com a parte contrária por uma relação jurídica base"; enquanto a indeterminidade é a característica fundamental dos interesses difusos, a determinidade a dos interesses coletivos; e direitos ou interesses homogêneos são os que têm a mesma origem comum, constituindo-se em subespécie de direitos coletivos.

Assim, feita a apresentação das características gerais dos direitos difusos, coletivos e individuais homogêneos, passa-se à análise do objeto e da legitimidade ativa para o ajuizamento da ação civil pública.

\section{AÇÃO CIVIL PÚBLICA: OBJETO E LEGITIMIDADE ATIVA}

Um dos instrumentos judiciais mais utilizados na tutela dos direitos difusos e coletivos, espécies de direitos transindividuais, assim como na defesa dos direitos individuais homogêneos, é a denominada ação civil pública.

A tutela dos interesses transindividuais foi inicialmente prevista pela Lei 7.347/1985, e originariamente, conforme art. $3^{\circ}$ da referida lei, possuía apenas conteúdo condenatório, com pedidos ordinários, cautelares e executórios. 
$\mathrm{Na}$ sequência, e visando à proteção dos direitos difusos, coletivos e individuais homogêneos, advieram, entre outras, a Lei 7.853, de 24-10-1989 (que disciplina a ação civil pública em defesa das pessoas portadoras de deficiências), a Lei 7.913, de 7-12-1989 (que trata da ação civil pública de responsabilidade de danos causados aos investidores no mercado de valores mobiliários), a Lei 8.069, de 13-7-1990 (que cuida da proteção judicial dos interesses difusos e coletivos da criança e do adolescente), a Lei 8.078, de 11-9-1990 (que dispõe sobre a defesa coletiva do consumidor em Juízo), a Lei 10.257, de 10-7-2001 (que disciplina a ordem urbanística), a Lei 10.741, de $1^{\circ}-10-2003$ (que trata da defesa dos idosos) e a Lei 11.340, de 7-8-2006 (que cuida da defesa dos interesses e direitos transindividuais da mulher) (REMEDIO, 2015, p 879).

Embora inexista um Código de Processo Coletivo a disciplinar as questões afetas à tutela coletiva, em consonância com o entendimento do Superior Tribunal de Justiça expressado quando do julgamento do Recurso Especial n. 1.106.515-MG (BRASIL, 2010), o art. 21 da Lei 7.347/1985 e o art. 90 da Lei 8.078/1990, "como normas de envio, possibilitaram o surgimento do denominado microssistema ou minissistema de proteção aos interesses ou direitos coletivos em sentido amplo, com o qual se comunicam, entre outras normas," o Estatuto do Idoso (Lei 10.741, de $1^{\circ}$-10-2003), o Estatuto da Criança e do Adolescente (Lei 8.069, de 13-7-1990), a Lei da Ação Popular (Lei 4.717, de 29-6-1965), a Lei de Improbidade Administrativa (Lei 8.429, de 2-6-1992) e outras normas que visam tutelar direitos dessa natureza, de maneira que os diversos instrumentos e institutos podem ser utilizados para propiciar sua adequada e efetiva tutela.

Ainda de acordo com o Superior Tribunal de Justiça, conforme referido no Recurso Especial n. 1.106.515-MG antes citado, apesar do reconhecimento doutrinário e jurisprudencial no sentido de que a nova ordem constitucional erigiu um autêntico concurso de ações entre os instrumentos de tutela dos interesses transindividuais, "a ação civil pública é o instrumento processual por excelência para a sua defesa”.

A ação civil pública possui aptidão para várias espécies de pedidos, sejam eles condenatórios, constitutivos positivos e negativos, declaratórios, tendo sempre em conta a satisfação do direito difuso, coletivo ou individual homogêneo que se busca proteger ou efetivar. 
A ação civil pública também pode se consubstanciar nos mais variados procedimentos judiciais, sempre em consonância com a legislação específica existente sobre a matéria e com o objeto defendido.

$\mathrm{E}$, diante da variedade de procedimentos e objetos, questiona-se se é possível a aplicação do instituto da reconvenção previsto no art. 343 do CPC/2015 em relação à ação civil pública, realçando-se desde logo que a matéria é bastante controvertida na doutrina e na jurisprudência.

Da mesma forma, seja com base no CPC/1973, seja com fundamento no CPC/2015, inexiste uniformidade de pensamento doutrinário e jurisprudencial a respeito da possibilidade da reconvenção na ação civil pública em face da natureza jurídica da legitimidade ativa para o ajuizamento da ação, uma vez que predomina o entendimento de que se trata de substituição processual.

A doutrina firmada sob a égide do CPC/1973 entendia que a legitimidade nas ações coletivas se exercitava de forma extraordinária, em especial pelo instituto da substituição processual.

Nesse sentido, Teori Albino Zavascki (2009, p. 64), ao tratar da tutela de direitos transindividuais por ação civil pública, leciona que:

Considerada a natureza transindividual dos direitos tutelados, não há como, em ação civil pública, imaginar a hipótese de legitimação ativa ordinária de que trata o art. $6^{\circ}$ do CPC, ou seja, a legitimação pessoal de quem se afirma titular do direito material. Tratando-se de direitos difusos ou coletivos (=sem titular determinado), a legitimação ativa é exercida, invariavelmente, em regime de substituição processual: o autor da ação defende, em nome próprio, direito de que não é titular.

O entendimento doutrinário expendido por Teori Albino Zavascki relativamente à natureza jurídica de substituição processual da legitimidade ativa para o ajuizamento da ação civil pública não sofreu alterações com o advento do CPC/2015.

Tradicionalmente, a legitimidade se opera de forma ordinária, ou seja, o sujeito ativo legitimado ordinariamente defende interesse próprio em nome próprio. Na legitimação extraordinária, em especial na substituição processual, que constitui a exceção em relação ao modelo tradicional, o sujeito ativo legitimado defende em nome próprio interesses de terceiros, sempre com autorização legal. 
E, na medida em que na ação coletiva a legitimidade ativa opera-se em substituição processual, indaga-se se o legitimado passivo da ação, através da reconvenção, pode acionar o legitimado extraordinário quando tenha algum pedido conexo com o objeto da ação civil pública ou diante de qualquer outro interesse jurídico que pretenda ver reconhecido judicialmente.

A resposta, em princípio, pode ser afirmativa, desde que atendidos determinados requisitos, entre os quais: o objeto do pedido da reconvenção deve ser direcionado ao substituído processual, o objeto da reconvenção deve ter natureza difusa, coletiva ou individual homogênea, e o substituto processual deve ter legitimidade extraordinária para responder pelo pedido reconvencional.

No tocante à legitimidade processual no processo coletivo, destaca-se que o Ministério Público é o legitimado institucional indicado pela Constituição Federal e sempre deverá participar da ação coletiva, mesmo que outro legitimado tenha iniciado a ação. O Ministério Público é legitimado em geral para a tutela de todos os tipos de interesses difusos e coletivos, nos termos do artigo 129, III, parte final da Constituição Federal.

Neste sentido, o magistério de Rodolfo de Camargo Mancuso (2016, p. 153):

\begin{abstract}
Inclinamo-nos pela interpretação ampliativa - ou, se quiser, construtiva - do disposto no art. 129, III, parte final, da CF: primeiro, ela é favorecida pelo critério gramatical, visto que o constituinte não condicionou a tutela de "outros interesses difusos e coletivos" ao discrimen legal; logo, não pode o intérprete estabelecer restrições onde não o tenha feito o legislador, segundo, é certo que algumas leis vieram cuidar especificamente da tutela judicial de certos interesses metaindividuais - dos deficientes físicos, dos investidores no mercado de capitais, dos consumidores, da criança e do adolescente, dos idosos, das raças e etnias -, mas daí não se extrai a conclusão de que o disposto no artigo 129, III, parte final, da CF seja "norma programática" ou de "eficácia contida".
\end{abstract}

Todavia, importante destacar que, de acordo com o art. $5^{\circ}$ da Lei 7.347/1985, além do Ministério Público, estão legitimados para a respectiva ação civil pública a Defensoria, a União, os Estados, Distrito Federal e os municípios, as autarquias, empresas públicas, fundações e sociedades de economia mista, além de associações que estejam constituídas há pelo menos um ano e que estejam incluídas dentro de suas finalidades institucionais a proteção ao patrimônio público e social, ao meio ambiente, ao consumidor, à ordem econômica, à livre concorrência e várias outras matérias. 
Em regra, o âmbito dos efeitos da substituição processual nas ações coletivas, como no caso da ação civil pública, extrapola a órbita individual, irradiando-se para o patrimônio de diversas pessoas.

Nesse sentido, conforme expressado pelo Superior Tribunal de Justiça quando do julgamento do Agravo Regimental no Agravo Regimental no Agravo de Instrumento n. 1.419.534-DF (BRASIL, 2016):

O Supremo Tribunal Federal ratificou o entendimento de que os efeitos da substituição processual em ações coletivas extravasam o âmbito simplesmente individual para irradiarem-se a ponto de serem encontrados no patrimônio de várias pessoas que formam uma categoria, sendo desnecessária a indicação dos endereços onde se encontram domiciliados os substituídos, uma vez que, logicamente, os efeitos de eventual vitória na demanda coletiva beneficiará todos os integrantes desta categoria, independente de onde se encontrem domiciliados (MS 23.769, Rel. Min. ELLEN GRACIE, Tribunal Pleno, julgado em 3/4/2002, DJ 30/4/2004).

No que se refere às características específicas, a legitimação para a ação civil pública é de natureza concorrente disjuntiva, sendo necessário verificar, mormente nos casos de legitimação das associações, sindicatos, fundações, a existência da chamada pertinência temática com o objeto discutido nos autos, fato que influenciará diretamente na conexão da matéria passível de reconvenção.

\section{RECONVENÇÃO: NATUREZA JURÍDICA, REQUISITOS E APLICAÇÃO AO PROCESSO COLETIVO}

O instituto processual da reconvenção tem natureza de ação e historicamente se identifica como uma das modalidades de resposta do réu no processo, seja com base no revogado CPC/1973 (arts. 297 e 315 a 318), seja com assento no CPC/2015 (art. 343), atualmente em vigor.

O fundamento tradicional da reconvenção sempre foi a economia processual e, desde que existam todos os requisitos para que o réu deduza pedido em face do autor, permite-se a utilização do instituto.

O CPC/1973 estatuía a respeito do instituto que: o réu podia reconvir ao autor no mesmo processo, toda vez que a reconvenção fosse conexa com a ação principal ou com o fundamento da defesa (art. 315, caput); não podia o réu, em seu próprio nome, reconvir ao 
autor, quando este demandasse em nome de outrem (art. 315, parágrafo único); não se admitia a reconvenção nas causas de procedimento sumaríssimo (art. 315, § $2^{\circ}$ ); oferecida a reconvenção, o autor reconvindo era intimado na pessoa de seu procurador para contestá-la no prazo de quinze dias (art. 316); a desistência da ação, ou a existência de qualquer causa que extinguisse a ação, não obstava ao prosseguimento da reconvenção (art. 317); e eram julgadas na mesma sentença a ação e a reconvenção (art. 318).

O CPC/2015, que revogou o CPC/1973, dispõe quanto ao instituto que: é lícito ao réu, na contestação, propor reconvenção para manifestar pretensão própria, conexa com a ação principal ou com o fundamento da defesa (art. 343, caput); o prazo para apresentação de resposta na reconvenção é de quinze dias; a desistência da ação ou a ocorrência de causa extintiva que impeça o exame do mérito não obsta o prosseguimento do processo reconvencional (art. 343, § $2^{\circ}$ ); a reconvenção pode ser proposta contra o autor e terceiro, assim como pode ser proposta pelo réu em litisconsórcio com terceiro (art. $343, \S \S 3^{\circ}$ e $4^{\circ}$ ); caso o autor seja substituto processual, o reconvinte deverá afirmar ser titular de direito em face do substituído, e a reconvenção deverá ser proposta em face do autor, também na qualidade de substituto processual (art. 343, $\S 5^{\circ}$ ); o réu pode propor reconvenção independentemente de oferecer contestação (art. 343, § $6^{\circ}$ ); e são devidos honorários advocatícios na reconvenção (art. $85, \S 1^{\circ}$ ).

Sob a égide do CPC/1973 a reconvenção seguia um regime de procedimento com necessidade de petição em apartado, que devia ser apresentada no mesmo prazo da contestação (arts. 297 e 299). Com o advento do CPC/2015, apesar da natureza e dos requisitos não terem sido modificados essencialmente, não há mais a necessidade de apresentação da reconvenção por meio de petição em apartado, razão pela qual deverá estar incluída na peça da contestação (art. 343).

Em última análise, a reconvenção é fruto do fenômeno da concentração de ações, privilegia a economia processual e permite uma análise ampla e sistematizada dos fatos levados ao Poder Judiciário, o que evita tratamento diverso e heterogêneo para situações que merecem análise conjunta e homogênea.

Na lição de Humberto Theodoro Júnior (2014, p. 437), “ao contrário da contestação, que é simples resistência à pretensão do autor, a reconvenção é um contra-ataque, uma verdadeira ação ajuizada pelo réu (reconvinte) contra o autor (reconvindo), nos mesmo autos”. Além dos elementos comuns exigidos para qualquer ação, a reconvenção 
possui certos requisitos específicos que devem ser atendidos, entre os quais destaca-se a qualidade da legitimidade de parte.

A respeito da questão, Humberto Theodoro Junior (2014, p. 438), em lição anterior ao CPC/2015, citando José Joaquim Calmon de Passos, assevera que:

Por outro lado, tanto na ação como na reconvenção, as partes devem atuar na mesma qualidade jurídica, de sorte que, se um age como substituto processual de terceiro, não poderá figurar em nome próprio na lide reconvencional. Em outras palavras, quem foi demandado em nome próprio não pode reconvir como representante ou substituto de outrem e vice-versa.

O novo Código de Processo Civil (BRASIL, 2015), apesar de não fazer menção às lides coletivas, trouxe no $\S 5^{\circ}$ do art. 343 o entendimento acima expendido, ao dispor que "se o autor for substituto processual, o reconvinte deverá afirmar ser titular de direito em face do substituído, e a reconvenção deverá ser proposta em face do autor, também na qualidade de substituto processual".

E, corroborando referida afirmação, conforme se depreende do estabelecido no art. 19 da Lei da Ação Civil Pública - Lei 7.347/1985, aplica-se à ação civil pública o Código de Processo Civil aprovado pela Lei 5.869/1973 (CPC/1973), naquilo em que não contrarie suas disposições. Atualmente o processo civil brasileiro é disciplinado pelo CPC/2015, que revogou o CPC/1973, sendo o estatuto adjetivo civil de 2015 aplicável à ação civil pública, consoante estatuído no art. 19 da Lei 7.347/1985.

Por outro lado, em que pese o disposto no art. 19 da Lei 7.347/1985, são raras as referências à tutela coletiva no $\mathrm{CPC} / 2015$, inclusive deixando o novo estatuto adjetivo civil de prever de forma clara e expressa sua aplicação supletiva e subsidiária na órbita de proteção dos interesses e direitos transindividuais, diferentemente do que se verifica no tocante a outras questões não relacionadas com os direitos difusos e coletivos, como as concernentes aos processos eleitorais, trabalhistas e administrativos, para as quais há expressa previsão legal para a aplicação do Código subsidiária e supletivamente, em conformidade com o disposto em seu art. 15.

Admitindo-se a possibilidade de aplicação da reconvenção nos processos coletivos, como a ação civil pública, vários são os requisitos exigidos para sua efetivação e implementação. 
Assim, nos processos coletivos em que o autor for substituto processual, este somente poderá ser demandado em reconvenção na qualidade de substituto processual dos respectivos titulares, os quais em geral são de difícil individualização, em especial quando a tutela coletiva objetivar a proteção dos direitos transindividuais, sejam eles difusos ou coletivos.

Outro requisito específico da reconvenção é a conexão. Ora, como não se pode admitir eventual reconvenção se não houver conexão entre os pedidos, e como a conexão é bastante difícil de se verificar nos processos coletivos, em especial quando relacionados com a proteção dos direitos transindividuais, também será de aplicação restrita a reconvenção.

Ainda no tocante aos requisitos específicos da reconvenção, também se pode citar a competência, pois somente será possível a reconvenção se o Juiz for competente para conhecer e julgar ambas as ações, ressalvadas as causas de incompetência relativa, as quais podem ser prorrogadas. Aqui cabe ressaltar eventuais diversidades de competência de Juízo em razão da amplitude do interesse difuso ou coletivo discutido no processo coletivo, especialmente na ação civil pública.

Por fim, e ainda no que concerne aos requisitos específicos, é necessário que em ambos os pedidos, ação e reconvenção, o procedimento seja o mesmo. Ademais, historicamente sempre foi vedada a reconvenção em certos ritos, como na ação de alimentos e no processo de execução. Também em relação às ações declaratórias não se admite o cabimento da reconvenção, pois a natureza da ação declaratória tem caráter dúplice.

\section{A RECONVENÇÃo NA AÇÃo CIVIL PÚBLICA}

Após a análise dos aspectos gerais relativos à reconvenção e das peculiaridades referentes à ação civil pública para tutela dos interesses coletivos, difusos e individuais homogêneos, pode-se afirmar, em princípio, que não há impedimento absoluto para a aplicação da reconvenção no procedimento da ação civil pública, em especial quando o objeto protegido forem os direitos individuais homogêneos.

Não se nega que a questão é bastante controvertida e que há diversos aspectos que poderão dificultar ou mesmo impedir o acesso à tutela jurisdicional reconvencional na ação civil pública. 
Tão especial e peculiar é a ação civil pública, cujo objeto é o interesse ou direito difuso, coletivo, ou individual homogêneo, que parte da doutrina e da jurisprudência, sob a égide do CPC/1973, afirmava que não era admissível a reconvenção em relação à ação.

Na doutrina, segundo José Antonio Remedio (2015, p. 888-889), não era admissível reconvenção em ação civil pública, tendo em vista que, nos termos do art. 315, parágrafo único, do CPC/1973, "não pode o réu, em seu próprio nome, reconvir ao autor, quando este demandar em nome de outrem".

Na jurisprudência, ao julgar a Apelação n. 0001766-40.2013.8.26.0291, relativa a tombamento de imóvel, decidiu o Tribunal de Justiça de São Paulo (SÃO PAULO, 2014) não ser cabível a reconvenção em ação civil pública, diante da vedação contida no parágrafo único do art. 315 do CPC/1973, no sentido de que não pode o réu, em seu próprio nome, reconvir ao autor, quando este demandar em nome de outrem.

Da mesma forma, ao julgar o Agravo de Instrumento 1.0693.14.003894-6/002, relacionado a ação civil pública de improbidade administrativa, decidiu o Tribunal de Justiça de Minas Gerais (MINAS GERAIS, 2015) não ser admissível a reconvenção em ação civil pública, uma vez que "o art. 315, do CPC, Código de Processo Civil, veda a reconvenção quando o autor demandar em nome de outrem".

O entendimento antes expressado, firmado sob a égide do CPC/1973, continua a ser aplicado mesmo com o advento do CPC/2015, de acordo com o entendimento de parte da doutrina e da jurisprudência.

Assim, na doutrina, consoante Hugo Nigro Mazzilli (2016, p. 439):

Por que os entes estatais e as associações, legitimados à propositura da ação civil pública ou coletiva, como regra geral, não podem ser réus nessas mesmas ações? Porque a substituição processual é matéria de direito estrito, e a lei só lhes conferiu a possibilidade de exercerem a substituição processual do grupo lesado no pólo ativo. Por isso é que não cabe ação civil pública ou coletiva contra o grupo lesado, nem mesmo por meio de reconvenção.

Na jurisprudência, ao julgar a Ação Civil Pública n. 0002661.29.2014.8.26.0238, relativa a matéria ambiental, expressou-se o Juiz Paula da Rocha e Silva Formoso, da Comarca de Ibiúna, nos seguintes termos (SÃO PAULO, 2017):

Quanto à reconvenção, a despeito do silêncio da Lei 7347/85 (Lei da Ação Civil Pública), é intuitivo que a possibilidade de oposição de reconvenção deve ser balizada pelos ditames do art. 343, Código de Processo Civil, no que 
se exige serem conexas a causa principal com a reconvencional, além de não poder o réu reconvir ao autor, quando este pleiteia em nome de outrem. A reconvenção oposta no presente feito inobserva ambos os requisitos. Primeiro, pela diversidade de causa de pedir ou objeto entre a reconvenção e a ação principal. E segundo, pela atuação da Fazenda Pública como legitimado extraordinário, demandando em nome de outrem, qual seja, a coletividade (art. $225, \mathrm{CR})$.

Por outro lado, sob a regência do CPC/1973, também eram vários os doutrinadores que defendiam a possibilidade da reconvenção nas ações coletivas, entre as quais a ação civil pública.

Nesse sentido, conforme Elpídio Donizetti e Marcelo Malheiros (2010, p. 324): “Trazendo esse raciocínio para as ações coletivas, é fácil concluir que a reconvenção deverá ser aceita quando o réu deduzir pretensão contra o grupo substituído em juízo, encaixando-se, dessa maneira, como nítido exemplo de ação coletiva passiva (derivada)”.

Da mesma forma, segundo Luis Guilherme Aidar Bondioli (2009, p. 329):

Os processos coletivos, por si, nada têm de incompatível com a reconvenção. $\mathrm{O}$ fato de o processo ter sido instaurado para tutela de direitos difusos, coletivos ou individuais homogêneos não impede que o réu nele introduza uma demanda sua. Todavia, para que essa demanda do réu seja viável, ela deve atender à exigência de coincidentes qualidades jurídicas entre as partes. No caso dos processos coletivos, isso significa que a demanda reconvencional deve veicular pretensão do réu dirigida aos efetivos titulares dos direitos difusos, coletivos ou individuais homogêneos em disputa, ou seja, dirigida aos substituídos. Nessas circunstâncias, não pode o réu formular pretensão que tenha em face do substituto processual.

A forma de pensar antes expressada também é sustentada por diversos doutrinadores após o advento do CPC/2015, que revogou o CPC/1973. Dessa maneira, de acordo com Fredie Didier Jr. e Hermes Zaneti Jr. (2016, p. 342):

Observado o $\$ 5^{\circ}$ do art. 343 do CPC-2015, a reconvenção, no caso, tem de veicular pretensão dirigida a grupo, e não ao legitimado extraordinário. Ora, o interesse de agir será averiguado a partir do interesse do grupo e será o grupo o beneficiado com a tutela, nada mais natural que o interesse contraposto ou pretensão na reconvenção seja também dirigido ao grupo e não ao substituto processual, que deve apenas figurar como legitimado ativo adequado para fins de tutela. Para cumprir essa exigência, é preciso compreender que o processo coletivo também pode ser passivo; ou seja, que é concebível a existência de uma situação jurídica cujo sujeito passivo seja um grupo. A reconvenção, então, será uma ação coletiva passiva. Reconvenção no processo coletivo também é uma ação coletiva; mas é uma ação coletiva passiva. 
Os referidos autores mencionam vários exemplos de situações fáticas onde se verifica a possibilidade de reconvenção em processos coletivos. Mais especificamente em situações cujo objeto é o interesse coletivo, os autores relatam (DIDIER JR.; ZANETI JR., 2016, p. 340) que:

\begin{abstract}
Basta pensar no exemplo das situações jurídicas coletivas ativas e passivas discutidas pelos sindicatos das categorias profissionais de empregados e empregadores; nas situações jurídicas ativas e passivas envolvendo o direito de greve por parte de uma categoria de servidores públicos e dever coletivo de voltar ao trabalho (não interrompendo a prestação de serviços essenciais, por exemplo); nas situações jurídicas ativas e passivas surgidas de conflitos pela ocupação de espaços urbanos para manifestações populares e estudantis, conflitos de terras, coletividade de vítimas e coletividade de autores de ato ilícito etc.
\end{abstract}

Ainda no que se refere à reconvenção, citando um exemplo de ação civil pública trabalhista tutelando interesses coletivos, os autores afirmam (DIDIER JR.; ZANETI JR., 2016, p. 342):

Imagine que um sindicato proponha uma ação declaratória de direito de greve; o sindicato réu reconvém, propondo uma ação possessória afirmando que o grupo substituído tem promovido invasões em imóveis seus. O caso é admissível, exatamente porque a reconvenção possessória é também uma ação coletiva.

Importante destacar que um dos argumentos normalmente utilizados para se impedir a reconvenção na ação civil pública em que a legitimação ativa se perfazia com o instituto da substituição processual era a existência do parágrafo único do artigo 315 do Código de Processo Civil de 1973. Entretanto, o novo Código de Processo Civil, mais especificamente em seu artigo 343, $\S 5^{\circ}$ (BRASIL, 2015), dispõe que "se o autor for substituto processual, o reconvinte deverá afirmar ser titular de direito em face do substituído, e a reconvenção deverá ser proposta em face do autor, também na qualidade de substituto processual”.

Em princípio, portanto, a questão da substituição processual no polo ativo da ação coletiva não é causa, somente por si, para afastar de plano a possibilidade de reconvenção em ação civil pública, desde que coincidam todos os outros requisitos específicos para tal, como a competência, o rito, a conexão, etc.

$\mathrm{O}$ atual instituto processual da reconvenção inovou ao possibilitar o alargamento do polo passivo da reconvenção, ou seja, ao permitir ao réu reconvir em face do autor e terceiro (artigo 343, 33 do CPC) e propor reconvenção em litisconsórcio com terceiro (art. 343, $\S 4^{\circ}$, 
do CPC). Apesar de tal inovação não possuir relação direta com possibilidade de reconvenção nas ações coletivas, o fato é que o instituto teve sua aplicação aumentada. Assim, a reconvenção, antes consubstanciada e fundamentada principalmente no princípio da economia processual, atualmente aparenta ter privilegiado a ideia de resolução de conflitos de forma homogênea, estando implícito no instituto da reconvenção a preferência por decisões dentro de um sistema processual que evite tutelas contraditórias.

Nesta linha de pensamento, ainda que de forma indireta, ao julgar o Agravo Interno $\mathrm{n}$. 1.0183.11.016502-8/003, admitiu o Tribunal de Justiça de Minas Gerais, sob a égide do CPC/2015, a possibilidade de apresentação de reconvenção em ação civil pública cominatória de obrigação de fazer, ao sufragar o entendimento no sentido de que "articulado pedido expresso pelo réu, para que o Município seja responsabilizado pelos gastos da adequação de caixa subterrânea, não poderia o pleito ser deduzido em contestação, apenas em sede reconvencional" (MINAS GERAIS, 2014).

Sob nossa ótica, desde que presentes os demais requisitos antes expendidos exigidos para o exercício da reconvenção, levando-se em conta o objeto protegido pela ação civil pública, se, de um lado, aparenta ser inviável a reconvenção em relação aos direitos difusos (assim entendidos os transindividuais, de natureza indivisível, de que sejam titulares pessoas intedeterminadas e ligadas por circunstâncias de fato) e aos direitos coletivos stricto sensu (assim entendidos os transindividuais, de natureza indivisível de que seja titular grupo, categoria ou classe de pessoas ligadas entre si ou com a parte contrária por uma relação jurídica base), por outro lado, tem-se como admissível a reconvenção quanto aos direitos individuais homogêneos (assim entendidos os decorrentes de origem comum, dotados de natureza individual e divisível).

\section{CONCLUSÃO}

O Código de Processo Civil de 2015 trouxe diversas alterações e inovações em relação às disposições constantes do Código de Processo Civil de 1973, como se verifica, por exemplo, no tocante ao instituto da reconvenção.

Enquanto o CPC/1973 dispunha que o réu não podia, em seu próprio nome, reconvir ao autor, quando este demandasse em nome de outrem (art. 315, parágrafo único), o CPC/2015 estatui que, caso o autor seja substituto processual, o reconvinte, afirmando ser 
titular de direito em face do substituído, deverá propor a reconvenção em face do autor, também na qualidade de substituto processual (art. 343, $\S 5^{\circ}$ ).

A mudança normativa deu ensejo à discussão sobre a admissibilidade da reconvenção nos processos coletivos, em particular na ação civil pública, uma vez que a legitimação ativa para o ajuizamento dessa modalidade de ação possui natureza de substituição processual.

A ação civil pública constitui importante instrumento judicial de tutela dos interesses difusos, coletivos e individuais homogêneos, sendo que, no Brasil, construiu-se doutrinária e jurisprudencialmente um microssistema de tutela coletiva, onde se busca, por vários meios procedimentais, a efetividade e garantia da defesa de interesses difusos, coletivos e individuais homogêneos dos mais variados conteúdos

Todavia, ainda prevalece como regra no ordenamento jurídico brasileiro a cultura de busca de tutelas individuais, tanto que o Código de Processo Civil de 2015 pouco ou quase nada dispôs a respeito da tutela coletiva de direitos.

No processo civil tradicional a regra da legitimidade ativa é a legitimidade ordinária, onde a própria parte defende interesse próprio em nome próprio. Entretanto, há casos específicos de legitimação extraordinária, como a substituição processual, sempre mediante previsão legal.

O instituto da substituição processual, como espécie de legitimação extraordinária, é defendido pela maioria da doutrina e da jurisprudência de nossos Tribunais, sendo amplamente aceita a legitimidade ativa dos entes legal e constitucionalmente indicados para a defesa da tutela coletiva na proteção dos direitos difusos, coletivos e individuais homogêneos, inclusive por meio da ação civil pública.

Em razão das peculiaridades dos direitos tutelados na ação civil pública, bem como em função da não coincidência entre o autor e os titulares dos respectivos direitos de natureza difusa, coletiva individual homogênea, parte da doutrina e da jurisprudência não aceita a possibilidade de reconvenção nos processos coletivos, em especial na ação civil pública.

A reconvenção sempre teve como fundamento principal a economia processual. Hodiernamente, porém, até mesmo em razão das novidades criadas pelo Código de Processo Civil de 2015, além da economia processual, percebe-se que o sistema processual privilegiou e incentivou técnicas de solução de lides de maneira uniforme, justamente para evitar soluções conflitantes. Ora, se um dos requisitos da reconvenção é justamente a conexão, em havendo esta, o sistema permite e caminha em algumas hipóteses para a possibilidade da 
reconvenção, mesmo nos processos coletivos, em que pesem as peculiaridades próprias, como se dá, por exemplo, em relação à proteção dos direitos individuais homogêneos.

Com efeito, um dos fundamentos para impedir a reconvenção era a existência do artigo 315, parágrafo único, do Código de Processo Civil de 1973. Porém, com o advento do Código de Processo Civil de 2015, foram criados novos institutos que nos fazem crer ter sido autorizada, ainda que de forma não ampla, a reconvenção nos casos de processo coletivo, em particular na ação civil pública, especificamente nos casos de substituição processual relacionados aos direitos individuais homogêneos.

Enfim, apesar de excepcional, não há como se negar a possibilidade de reconvenção na ação civil pública, particularmente quando o objeto da tutela coletiva forem os direitos individuais homogêneos.

Evidente que a questão não é pacífica na doutrina e na jurisprudência. Entretanto, ante o dispositivo processual constante do artigo 343, § 5 , do CPC/2015, pode-se afirmar que há campo fértil para que o instituto da reconvenção na ação civil pública passe a ter maior aceitação doutrinária e aplicação concreta pelos tribunais pátrios.

Pode-se também asseverar ser mais aceitável a possibilidade de reconvenção na ação civil pública cujo objeto seja a defesa de interesses individuais homogêneos. No tocante às ações civis públicas cujo objeto seja a defesa dos direitos difusos ou dos direitos coletivos em sentido estrito, pela natureza do direito defendido, de caráter transindividual e indivisível, fica bastante difícil imaginar situação que permita a aplicação da reconvenção, embora, como visto no corpo da pesquisa, vários autores defendam a possibilidade da reconvenção mesmo nessas hipóteses.

Em síntese, apesar de bastante controvertida a matéria, em tese tem-se como admissível a interposição de reconvenção na ação civil pública, particularmente quando o objeto da ação forem os direitos individuais homogêneos, desde que reunidos os demais requisitos processuais exigidos para tanto, não sendo cabível o instituto, porém, em regra, quando o objeto protegido forem os direitos difusos e coletivos.

Ora, o Direito, apesar de conservador por natureza, na seara coletiva sempre foi vanguardista e desbravador, criando institutos muitas vezes originais, razão pela qual, muito provavelmente, o processo coletivo cada vez mais evoluirá e proporcionará a garantia e eficácia dos atuais e vindouros direitos coletivos, difusos e individuais homogêneos, inclusive 
com a possibilidade de aplicação cada vez mais ampla do instituto da reconvenção em relação às ações coletivas, entre as quais a ação civil pública.

\section{REFERÊNCIAS}

BONDIOLI, Luis Guilherme Aidar. Reconvenção no processo civil. São Paulo: Saraiva, 2009.

BRASIL. Lei n. 5.869, de 11 de janeiro de 1973 - Código de Processo Civil. Disponível em: <http://www.planalto.gov.br/ccivil_03/Leis/L5869.htm>. Acesso em 14 maio 2017.

Lei n. 7.347, de 24 de julho de 1985. Disponível em: <http://www.planalto.gov.br/ccivil_03/leis/L7347orig.htm>. Acesso em 14 maio 2017.

Lei n. 8.078, de aa de setembro de 1990. Disponível em: <http://www.planalto.gov.br/ccivil_03/leis/L8078.htm>. Acesso em 14 maio 2017.

. Lei n. 13.105, de 16 de março de 2015 - Código de Processo Civil. Disponível em: <http://www.planalto.gov.br/ccivil_03/_ato2015-2018/2015/lei/L13105.htm>. Acesso em 14 maio 2017.

Superior Tribunal de Justiça. Agravo Regimental no Agravo Regimental no Agravo de Instrumento n. 1.419.534-DF. Relator Ministro Herman Benjamin. Brasília: DJe, 3 fev. $2016 . \quad$ Disponível em: $<$ https://ww2.stj.jus.br/processo/revista/documento/mediado/?componente=ATC\&sequencial $=52915927 \&$ num_registro $=201100994684 \&$ data $=20160203 \&$ tipo $=5 \&$ formato $=P D F>$. Acesso em 14 maio 2017.

Superior Tribunal de Justiça. Recurso Especial n. 1.106.515-MG. Relator Ministro Arnaldo Esteves de Lima. Brasília: DJe, 2 fev. 2011. Disponível em: <https://ww2.stj.jus.br/processo/revista/documento/mediado/?componente=ATC\&sequencial $=13506230 \&$ num_registro=200802595631\&data $=20110202 \&$ tipo $=5 \&$ formato $=P D F>$. Acesso em 4 maio 2017.

Supremo Tribunal Federal. Recurso Extraordinário n. 163.231-SP. Relator Ministro Maurício Corrêa. Brasília: Diário de Justiça, 29 jun. 2001, p. 55.

CERQUEIRA, Marcelo Malheiros. Curso de processo coletivo. São Paulo: Atlas, 2010.

DIDIER JR., Fredie; ZANETI JR., Hermes. Curso de direito processual civil: processo coletivo. 10 ed. Salvador: JusPodivm, 2016.

DONIZETTI, Elpídio; CERQUEIRA, Marcelo Malheiros. Curso de processo coletivo. São Paulo: Atlas, 2010.

MANCUSO, Rodolfo de Camargo. Interesses difusos: conceito e legitimação para agir. São Paulo: Revista do Tribunais, 2011.

Ação civil pública. 14. ed. São Paulo: Revista dos Tribunais, 2016.

MAZZILLI, Hugo Nigro. A defesa dos interesses difusos em juízo. 29. ed. São Paulo: Saraiva, 2016. 
MINAS GERAIS. Tribunal de Justiça de Minas Gerais. Agravo de Instrumento 1.0693.14.003894-6/002. Relator Desembargador Marcelo Rodrigues, publicado em 27 jul. 2015.

. Tribunal de Justiça de Minas Gerais. Agravo Interno n. 1.0183.11.016502-8/003 Conselheiro Lafaiete. Relator Desembargador Raimundo Messias Júnior, publicado em 6 mar. 2014.

REMEDIO, José Antonio. Direito administrativo. 2. ed. São Paulo: Verbatim, 2015.

SÃO PAULO. Comarca de Ibiúna do TJSP. Ação Civil Pública 0002661-29.2014.8.26.0238. Juiz Paula da Rocha e Silva Formoso. Disponível em: <https://www.jusbrasil.com.br/diarios/documentos/328441896/andamento-do-processo-n0002661-2920148260238-acao-civil-publica-27-04-2016-do-tjsp>. Acesso em 11 maio 2017.

Tribunal de Justiça de São Paulo. Apelação n. 0001766-40.2013.8.26.0291. Relator Desembargador Leme de Campos. São Paulo, julgado em 26 maio 2014. Disponível em: $<$ https://esaj.tjsp.jus.br/cjsg/getArquivo.do?cdAcordao=7596686\&cdForo=0\&vlCaptcha=mfk ks>. Acesso em 5 maio 2017.

THEODORO JUNIOR, Humberto. Curso de direito processual civil. 55. ed. Rio de Janeiro: Forense, 2014, vol. I.

ZAVASCKI, Teori Albino. Processo coletivo: tutela de direitos coletivos e tutela coletiva de direitos. 4. ed. São Paulo: Revista dos Tribunais, 2009. 